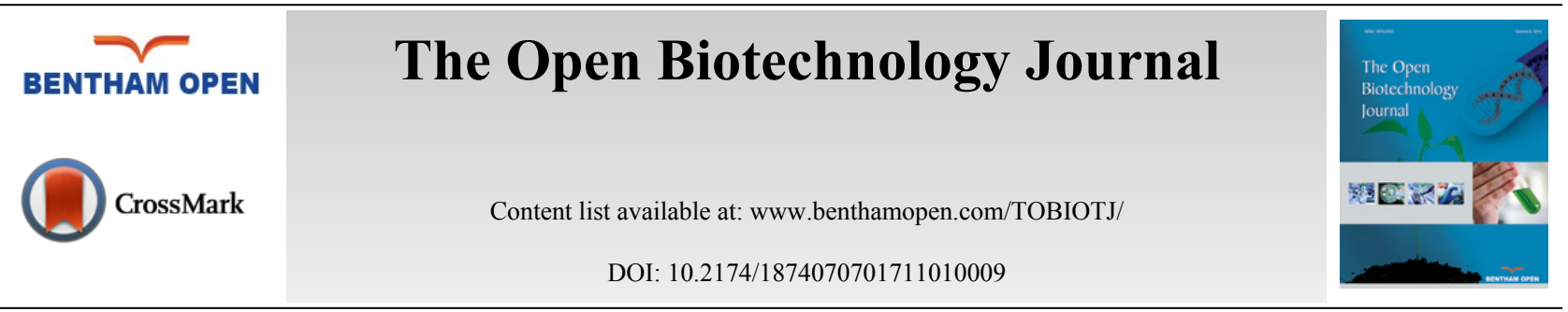

RESEARCH ARTICLE

\title{
Flower Bud Differentiation and Development of 'Jinsi No.4' Jujube (Ziziphus jujuba Mill.) in Hunan Province of Southern China
}

\author{
Feng Zou ${ }^{1}$, Jinghua Duan ${ }^{2}$, Huan Xiong ${ }^{1}$, Deyi Yuan ${ }^{1, *}$, Lin Zhang ${ }^{1}$ and Genhua Niu ${ }^{1,3}$ \\ ${ }^{I}$ The Key Laboratory of Cultivation and Protection for Non-wood Forest Trees, Ministry of Education, Central South \\ University of Forestry and Technology, Changsha, Hunan, 410004, P. R. China \\ ${ }^{2}$ Chinese Academy of Forestry, Beijing 100091, P.R. China \\ ${ }^{3}$ Texas A\&M AgriLife Research Center at El Paso, Texas A\&M University System, 1380 A\&M Circle, El Paso, TX \\ 79927, USA
}

\begin{abstract}
Ziziphus jujuba Mill. is one of the most important fruit crops and has been cultivated in China for more than 4000 years. $Z$. jujuba fruit is rich in nutritional and medicinal values. Compared to other wood fruits, $Z$. jujuba is unique in its flowering and fruiting characteristics. Floral buds differentiation and formation of $Z$. jujuba is an essential process that affects yield. Z. jujuba 'Jinsi No.4' blooms profusely, yet its final yield is low. In this study, the floral bud differentiation and development of 'Jinsi No.4' were examined by paraffin section. Results showed that the floral buds of 'Jinsi No.4' differentiated in the current year and started from early April. The duration of a single flower differentiation was short, taking only 7 days for maturation of flowers buds. Floral bud differentiation of 'Jinsi No.4' can be divided into six stages, i.e., pre-differentiation, initial differentiation, sepal differentiation, petal differentiation, stamen differentiation, and pistil differentiation. Flower development experienced seven stages, i.e., alabastrum, alabastrum break, sepal flattening, petal flattening, stamen flattening, filament withering, and ovule swelling. Dysplasia was observed in some floral organs in Z. jujuba 'Jinsi No.4', suggesting that the dysplasia of floral organs may be one of the main reasons for low yields. Our findings on flower bud development in 'Jinsi No.4' will contribute to its production and flowering management in Hunan area of southern China.
\end{abstract}

Keywords: Bud differentiation, Floral organ, fruit crop, Ziziphus jujuba 'Jinsi No.4'.

\section{INTRODUCTION}

Jujube (Ziziphus jujuba Mill.), a member of the Rhamnaceae family, a native fruit tree of China, which has been cultivated for thousands of years [1 - 3]. It is one of the world's major fruit crops grown in India, Russia, America, the Middle East, southern Europe, South Korea, Japan, and China [4 - 6]. Z. jujuba tree is characterized with barrentolerance, wide adaptability. Besides, the high amounts of vitamin A, C and B complexes, and minerals in jujube fruits [7]. It is also a very important source of income for farmers in mountainous regions [8, 9].

Unlike apples or peaches, jujubes do not have big, showy flowers [10]. Z. jujuba floral buds rapidly differentiate and bloom in one growing season, which is unique and different from most fruit trees [8]. Floral bud differentiation is critical to the production of Z. jujuba because it directly influences the number of floral buds and fruits, and its subsequent yield [11].

Z. jujuba 'Jinsi No.4' was originated in the Yuncheng County, ShanXi Province, China. As a high-value, well known, and first grade product and rare species, the fruit of $Z$. jujuba has a sugar content of $22.75 \%$, an acid content of $0.368 \%$, soluble solids content of $26.5 \%$, Vc (Vitamin C) content of $292.5 \mathrm{mg} / 100 \mathrm{~g}$, and the edible percentage is as

\footnotetext{
* Address correspondence to this author at The Key Laboratory of Cultivation and Protection for Non-wood Forest Trees, Ministry of Education, Central South University of Forestry and Technology, Changsha, Hunan, 410004, P. R. China; Tel: +86 -073185623406; Fax: +86 -073185623406; E-mail: csuftyuanyi@126.com
} 
high as $97 \%$. Since 1980 s, Z. jujuba 'Jinsi No.4' has been gradually introduced into over 10 provinces and cities across China. Z. jujuba was highly valued because of its early and large fruit with thin peel, thick pulp, sweet taste, as well as special flavor [12]. In our previous study, Zhiqiang Han et al. [13] found that 'Jinsi No.4' displayed a large number of flowers, but with low yields in the productivity. Deyi Yuan et al. [14] also indicated the highest percentage of the flowers fallen, which was $76.89 \%$ in Z. jujuba 'Hunanjidanzao'. Feng Zou et al. [12] described male and female gametophytes in Z. Jujuba 'Jinsi No.4'. Studies on flower differentiation processes have both a basic and applied interest. Therefore, understanding the floral initiation and differentiation of $Z$. jujuba is crucial for promoting yield. However, little is known regarding flower bud differentiation of jujube 'Jinsi No.4'. Thus, the main objective of this paper was to determine the time of flower bud differentiation and developmental stages of the flower organs in 'Jinsi No.4' jujube in Hunan province of Southern China.

\section{MATERIAL AND METHODS}

The experiment was carried out in the Z. jujuba germplasm resource pool, Hengyang, Hunan Province, China. The experimental plot was located on a hill with red soil located at longitude of eastern $112^{\circ} 18^{\prime} 54^{\prime \prime}$, latitude of northern $26^{\circ} 54^{\prime} 48^{\prime \prime}$, and altitude of $70 \mathrm{~m}[12]$.

Three plants of eight year-old Z. jujuba 'Jinsi No.4' with normal flowering and fruiting were used. From April to June of 2010 and 2011, three fruit-bearing shoots of jujube were cut every day from the middle section of the tree crown while fruiting sections were germinated until the shoots of jujube were visible, and cutting three per day when the length of fruit bearing shoots of jujube was greater than $3 \mathrm{~cm}$. The third and fourth nodes of floral buds were picked as the samples. In order to record the detail of the progresses of the flower development, ten of the materials were observed for external morphological features and photographed with a SZX-16 stereomicroscope (Olympus, Japan). The other ten of the samples were fixed in FAA solution (5\% formalin, 5\% acetic acid, 90\% alcohol, by volume), and stored at $4{ }^{\circ} \mathrm{C}$ [15]. Paraffin sectioning followed the methods introduced by Feng Zou et al. [16], dehydrated through an ethyl-alcohol series, embedded in paraffin with a $58-60{ }^{\circ} \mathrm{C}$ melting point, and sectioned at a thickness of $10 \mu \mathrm{m}$ by the microtome. The sections were stained with hematoxylin-eosin Y. The sections were observed and photographed by a BX-51 microscope (Olympus, Tokyo, Japan) [3].

\section{RESULTS AND ANALYSIS}

\subsection{Floral Development of a Single Flower}

Floral buds of 'Jinsi No.4' grew in the leaf axils of shoots of jujube being protected by the stipules. Flower buds differentiated with the growth of fruit-bearing shoots of jujube, at a higher differentiation rate and shorter differentiation period in a single flower, compared to other fruit trees. According to the morphological features during differentiation, the floral bud differentiation process of 'Jinsi No.4' could be divided into the following six stages.

\section{(1) Pre-differentiation Period}

Before the appearance of floral bud primordium, there were two bracts on both sides of the axillary bud, and then pointed circular shaped floral bud primordium. Prior to the appearance of the latter floral bud primordium, one bract appeared on both sides of the axillary bud (Fig. 1A).

\section{(2) Initial Differentiation Period}

After its emergence, floral bud primordium of 'Jinsi No.4' was pointed and circular in shape initially, and was followed by circle, swells and bulges, and then oblate dome shapes (Fig. 1B).

\section{(3) Sepal Differentiation Period}

The floral bud primordium of 'Jinsi No.4' quickly enlarged, as a result of rapid cell division. Cells around the lower part of the growth cones divided quickly. The formed flattened center and projected periphery of floral primordium was sepal primordium (Fig. 1C).

\section{(4) Petal Differentiation Period}

The sepal base of 'Jinsi No.4' enlarged, expanded upwards till a certain length, and then bent inwards. At the same time, enation of sepal primordium, i.e., sepal primordium, appeared at the base of the sepal (Fig. 1D and E). 


\section{(5) Stamen Differentiation Period}

The floral bud primordia and other enations continued growing. Buds base was connected to branches. There were new enations, i.e., the enation of stamen primordial, on the inner side of the petal primordial, thus indicating the start of stamen differentiation (Fig. 1F and $\mathbf{G}$ ).

\section{(6) Pistil Differentiation Period}

The oval-shaped floral bud of 'Jinsi No.4'elongated and slightly concaved inwards at the center. The petal and stamen primordial continued to extend, forming circular enations at the base center, i.e., pistil primordia (Fig. 1H and I). Pistil primordia gradually stretched upwards, thickened, and lengthened to form floral style, indicating the end of single flower differentiation. From the formation of visible projected fruit bearing shoots of jujube bract (April $23^{\text {th }}$ ) to the formation of pistil primordia (April $30^{\text {th }}$ ), it took seven days for the differentiation of single flower of 'Jinsi No.4'. After the pistil differentiation, with the extending and enlarging of petals of the central flowers, stamens gradually matured, forming anther at the top and extending filaments to the bottom. Pistil gradually matured as well, with the stigma splitting in two and forming ovary chamber (Fig. 1J).
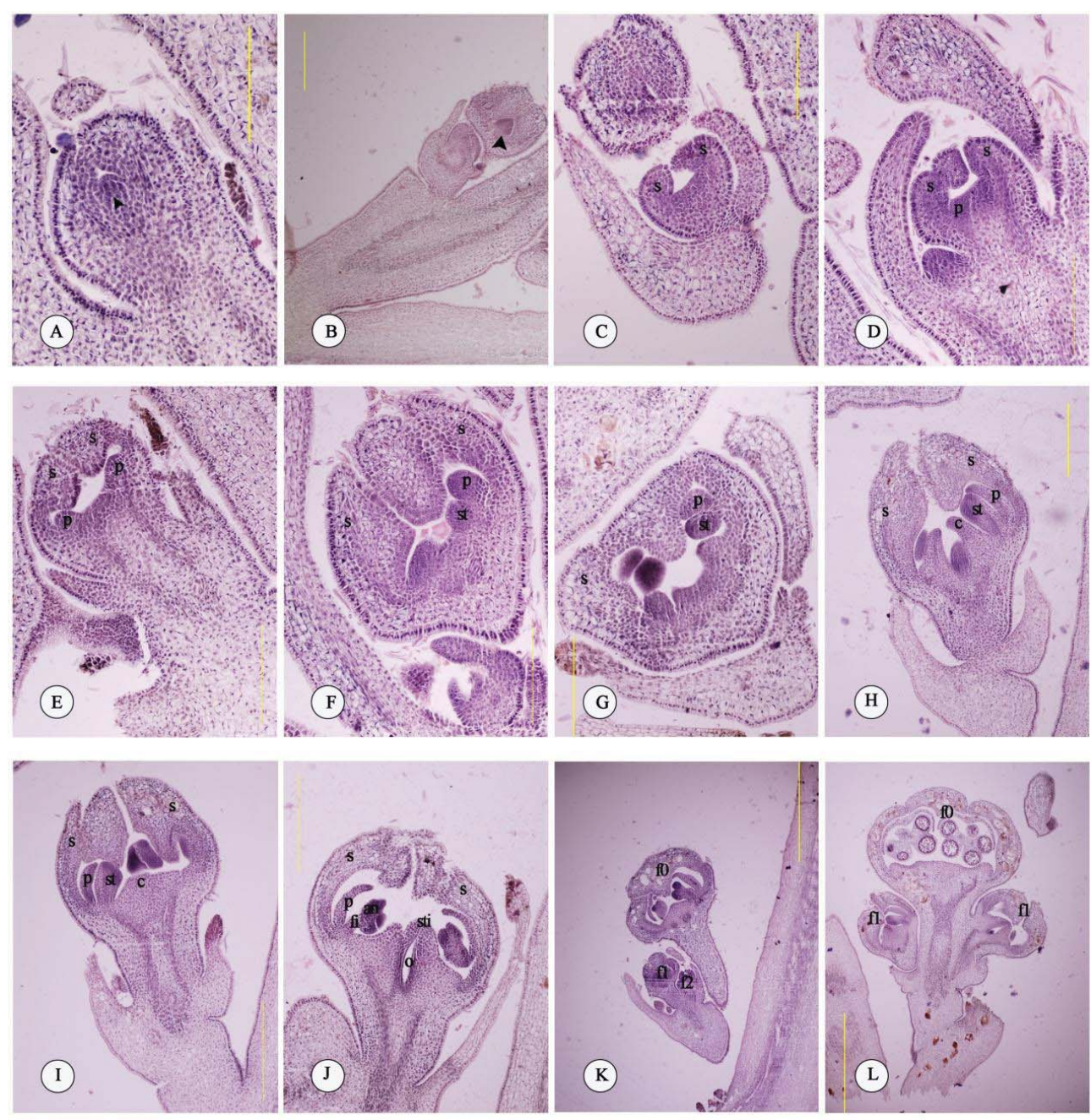

Fig. (1). Anatomical changes in the flower bud during differentiation and development in 'Jinsi No.4' jujube. A, Longitudinal section showing the period of pre-differentiation in early April. B, Longitudinal section showing the initial stage. C, Longitudinal section showing the period of sepal differentiation. D-E, Longitudinal section showing the period of petal differentiation. F-G, Longitudinal section showing the period of stamen differentiation with petal, sepal and stamen. H-J, Longitudinal section showing the period carpel differentiation with petal, sepal, stigma, filament, anther and ovary. K-L, Longitudinal section showing the inflorescence differentiation with f0, f1 and f2. an: anther; s: sepal; sti: stigma; p: petal; st: stamen; c: carpel; o: ovary. fi: filament. f0, f1 and f2 represent 0,1 and 2 level flowers of inflorescence, respectively. 


\subsection{Inflorescence Differentiation}

Z. jujuba flowers were dichasial inflorescence or incomplete dichasial inflorescence. The differentiation of inflorescence occurred at the same time as single flower. The Figs. (1K and 2C) displayed the pistil differentiation period of grade 0 flowers, the stamen differentiation period of grade 1 flowers, and the sepal differentiation period of grade 2 flowers. On the other hand, as shown in Figs. (1L) and (2A and B) showed the completed floral bud differentiation of grade 0 flowers, and the beginning of pistil differentiation of grade 1 flowers. For flowers in inflorescence, differentiation happened at the center first, then gradually on the side. With the appearance of the floral primordia, each development stage lasted about 1 day. There were 1 to 15 flowers per inflorescence, with an average of 7 flowers; therefore, it took about 7 to 20 days for the differentiation of 'Jinsi No.4' inflorescence.

\subsection{Flower Development}

The time of flower bud differentiation and the developmental stages of the floral buds of cultivar 'Jinsi No.4' in Hunan between 2010 and 2011 is presented in Table 1. As shown, in Hengyang, jujube bract initiated on April $9^{\text {th }}$, and fruit-bearing shoots of jujube initiated on April $20^{\text {th }}$. During the fast growing period of fruit bearing shoots of jujube, some alabastrum developed and blossomed on May $23^{\text {th }}$, beginning the early flowering period on May $30^{\text {th }}(25 \%$ flower blossom in this period). Full blossom period (blossom rate greater than $50 \%$ ) started on June $10^{\text {th }}$, lasting 15 days. The end flowering period (blossom rate less than $50 \%$ ) began on June $25^{\text {th }}$.

Table 1. Sequence of events during the differentiation and inner development of flower bud of 'Jinsi No.4' jujube in Hunan between 2010 and 2011.

\begin{tabular}{|c|c|}
\hline Date & Bud / flower Development Stage \\
\hline April $9^{\text {th }} \sim 22^{\text {th }}$ & Pre-differentiation \\
\hline April $23^{\text {th }} \sim 25^{\text {th }}$ & Initial differentiation \\
\hline April $25^{\text {th }} \sim 27^{\text {th }}$ & Sepal differentiation \\
\hline April $27^{\text {th }} \sim 28^{\text {th }}$ & Petal differentiation \\
\hline April $28^{\text {th }} \sim 29^{\text {th }}$ & Stamen differentiation \\
\hline April $29^{\text {th }} \sim 30^{\text {th }}$ & Pistil differentiation \\
\hline May $1^{\text {th }} \sim 20^{\text {th }}$ & Alabastrum \\
\hline May $21^{\text {th }} \sim 22^{\text {th }}$ & Alabastrum break \\
\hline May $23^{\text {th }} \sim 24^{\text {th }}$ & Sepal flattening \\
\hline May $24^{\text {th }} \sim 25^{\text {th }}$ & Petal flattening \\
\hline May $25^{\text {th }} 26^{\text {th }}$ & Stamen flattening \\
\hline May $26^{\text {th }} 27^{\text {th }}$ & Filament withering \\
\hline May $27^{\text {th }} 29^{\text {th }}$ & Ovule swelling \\
\hline May $30^{\text {th }} \sim$ June $9^{\text {th }}$ & Early flowering period \\
\hline June $10^{\text {th } \sim \text { June } 24^{\text {th }}}$ & Full blossom period \\
\hline June $25^{\text {th }} \sim$ July $10^{\text {th }}$ & The end of flowering period \\
\hline & \\
\hline & \\
\hline
\end{tabular}

Flower development of 'Jinsi No.4' included the alabastrum development and floral blossom stages. Floral buds that developed early entered alabastrum stages after the completion of differentiation (Fig. 2A-C), with leaves expanding with the growth of fruit-bearing shoots of jujube, and with alabastrum increasing gradually as well. In early May, $50 \%$ of leaf axil alabastrums were visible, with the alabastrum stage lasting 20 days. Floral blossom could be divided into six periods: alabastrum break (sepals separated from each other) (Fig. 2D and E), sepal flattening (floral plate started to secrete nectar) (Fig. 2F and G), petal flattening (stigma divided into two, pollination started) (Fig. 2H), stamen flattening (Fig. 2I), filament withering (Fig. 2J), and ovule swelling (Fig. 2K). Dysplastic flowers, in which the sepal does not flatten and inclines upwards, withered and yellowed, are affected by anthocaulus (Fig. 2L).

\section{DISCUSSION}

The floral differentiation of fruit trees involves the transformation of leaf buds on branches into a floral bud [17]. Bud differentiation was observed to be more complex than the differentiation of vegetative organs [18, 19]. Many 
studies of Z. jujuba floral differentiation have been conducted. Qu Ze-zhou et al. [8] observed the biological features of $Z$. jujuba, dividing floral differentiation of $Z$. jujuba cv. Mayazao into six stages. Chen Yi-jin [20] also reported floral differentiation of Z. jujuba cv. Huizao. Meng Yu-ping et al. [19] and Wang Li-hong et al. [21] divided the floral differentiation of $Z$. jujuba cv. Hupingzao into five stages, including the floral primordium differentiation, sepal differentiation, petal differentiation, stamen differentiation, and pistil differentiation. Noemi and Bert [22] described flower development of Z. jujuba mauritiana in detail from floral primordium differentiation to blossom, and divided the process into eleven stages by the SEM and paraffin sections. Michal Meir et al. [23] reported the developmental stages of fruit bearing shoots of Z. Jujuba cv. Ben-Li. According to our observations, the floral bud differentiation process of 'Jinsi No.4' could be divided into six stages, i.e., pre-differentiation, initial differentiation, sepal differentiation, petal differentiation, stamen differentiation, and pistil differentiation periods. Similar results were reported in 'Mayazao' [8], 'Huizao' [20], and 'Xinlezao' [11]. During the flower development process, we divided flower development of 'Jinsi No.4' into seven stages, i.e., alabastrum, alabastrum break, sepal flattening, petal flattening, stamen flattening, filament withering, and ovule swelling. Different from 'Jinsi No.4' occurred during petal flattening stage, the stigma bi-split, floral plate nectar secretion, and pollination of Z. jujuba cv. Qiyuexian occurred during sepal flattening stage [24].
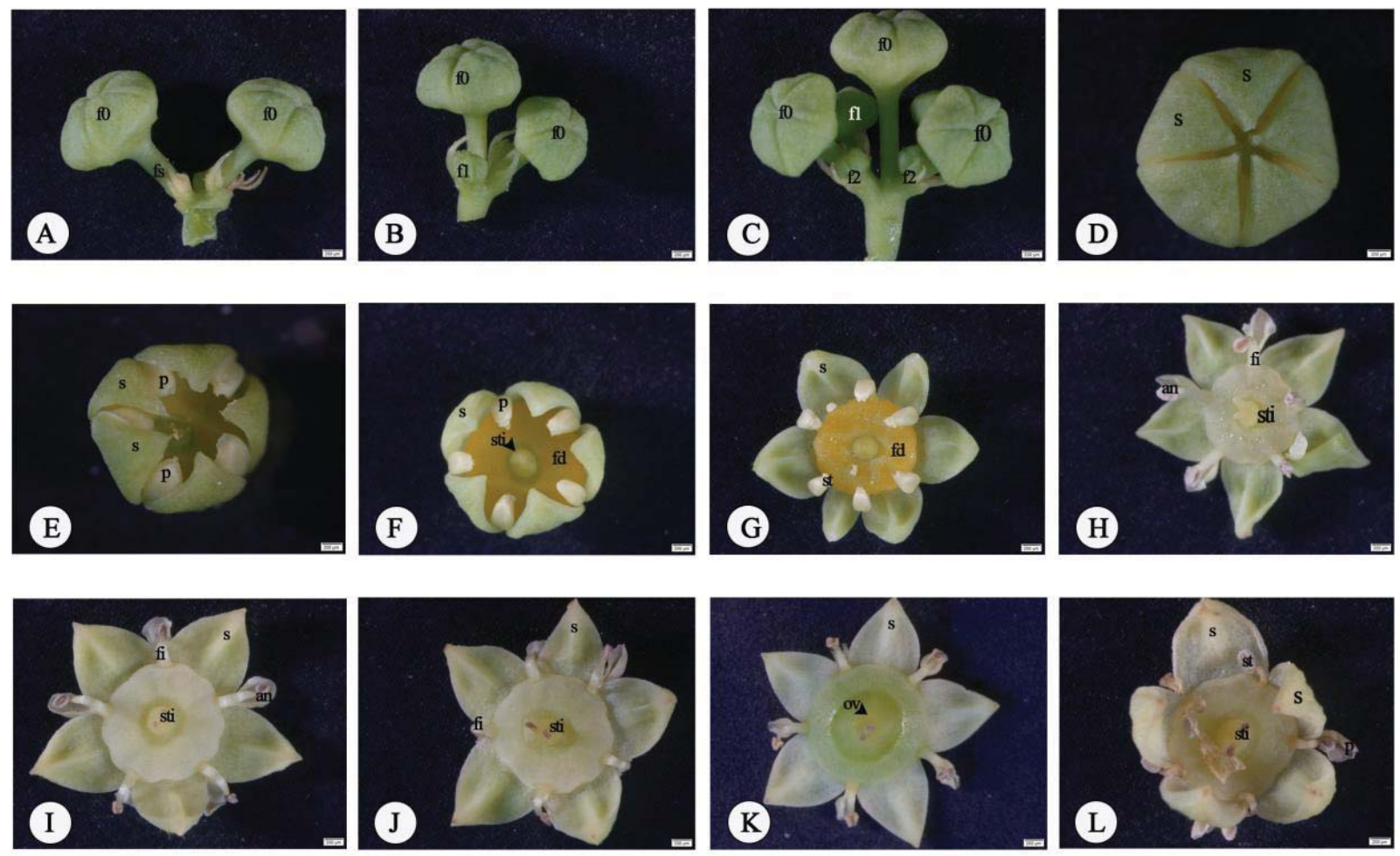

Fig. (2). Flower development stages of 'Jinsi No.4' jujube. A-C, Jujube flower showing the bud period with f0, f1 and f2. D-E, Jujube flower showing the period of bud split with five sepals and petals. F-G, Jujube flower showing the period of sepal spread with one stigma, five petals located between the sepals and five stamens attached to the edge of the nectary disk. H, Jujube flower showing the period of petal spread with one stigma, and five filament and anthers. I, Jujube flower showing the period of stamen spread. J, Jujube flower showing the period of filament wilting. K, Jujube flower showing the period of ovary inflated. L, Jujube flower showing the flower dysplasia. an: anther; s: sepal; sti: stigma; p:petal; st: stamen; ov: ovary; fi: filament; fd: flower disc; fs: flower stalk. f0, f1 and $\mathrm{f} 2$ represent 0,1 and 2 level flowers of inflorescence, respectively.

In our study, we observed that floral buds of 'Jinsi No.4' differentiated the current year in Hunan Province, Southern China. The time of a single flower differentiation was short, just 7 days. Niu Hui-ling et al. [24] reported that floral bud differentiation of Z. jujuba cv. Qiyuexian needed 11 days in Shanxi province of Northern China. This difference may be explained by differences in varieties or environmental conditions.

To our knowledge, the mechanism of floral bud differentiation has been concerned with overcoming alternate bearing, improving fruit quality, and advancing the fruiting of young trees. Jujube is known to produce erratic fruits which lead to lower yield [7]. There are a number of reasons for erratic fruit production in jujube including: flower organ abortion [3, 14], poor pollination and fertilization [25 - 27] and insufficient nutrients [11, 19, 21]. Feng Zou et al. 
[3] studied floral biology of jujube and found $25.80 \%$ aborted ovules, which were likely the cause of the low seed set in Jujube 'Lizao' during reproductive organ development. As we know, quality of the reproductive organs depends on the factors and conditions for flower bud formation, which in turn influences the quantity and quality of fruit production. $Z$. jujuba floral bud differentiated with the growth of shoots and branches, with a long period of differentiation and blossom, which also consumed many nutrients. Floral bud differentiation of Jujube was closely linked to nutrient content $[11,19,21]$. In our experiment, we observed that some floral organs of 'Jinsi No.4' had poor development, which may attribute to low yields. Therefore, future research is needed to determine whether the dysplastic flowers were caused by nutrients limitations. By means of monitoring the development and quality of the flower buds, it is possible to predict the potential yield and provide necessary agro-technical measures in the year preceding flowering. In the process of bud differentiation of 'Jinsi No.4', foliar spraying should be provided in April to avoid malnutrition.

\section{CONCLUSION}

Floral bud differentiation of 'Jinsi No.4' can be divided into six stages, i.e., pre-differentiation, initial differentiation, sepal differentiation, petal differentiation, stamen differentiation, and pistil differentiation. Flower development experienced seven stages, i.e., alabastrum, alabastrum break, sepal flattening, petal flattening, stamen flattening, filament withering, and ovule swelling. We observed that some of the dysplasia of floral organs in $Z$. jujuba 'Jinsi No.4', suggesting that the dysplasia of floral organs may be one of the main reasons for low yields. In the process of bud differentiation of 'Jinsi No.4', we should supply sufficient nutrients to avoid malnutrition in the April. Our results provided the details of flower bud development in 'Jinsi No.4' in Hunan, which will contribute to its production and management.

\section{CONFLICT OF INTEREST}

The authors confirm that this article content has no conflicts of interest.

\section{ACKNOWLEDGEMENTS}

The authors are grateful to Ting Liao, Yazhi Feng, Weihua Duan and Xiao Zhang. This research was supported by the National Science and Technology Pillar Program (2013BAD14B03), the Open Fund Project of Innovation Platform of Hunan Province (No.15K149) and the Special Funds for Forestry Scientific Research in the Public Interest (201204407).

\section{REFERENCES}

[1] Li Z. Studies on bud structure and bud developmetal characteristic of Chinese jujuba (Ziziphus jujuba Mill.). Acta Hortic Sin 1964; 4: 353-8.

[2] Zou F, Duan J, Yuan D, et al. Floral biology of Chinese jujube (Ziziphus jujuba Mill.) I: The formation of microspores and development of male gametes. Adv J Food Sci Technol 2015; 9: 220-6. [http://dx.doi.org/10.19026/ajfst.9.1998]

[3] Zou F, Duan J, Yuan D, et al. Floral biology of Chinese jujube (Ziziphus jujuba Mill.) II: The formation of megasporogensis and development of female gametes. Adv J Food Sci Technol 2015; 9: 556-61. [http://dx.doi.org/10.19026/ajfst.9.1965]

[4] Ma C, Ye X, Chen Y, et al. Anatomical observations of adventitious bud regeneration from leaf explants of Ziziphus jujuba Mill. 'Huizao'. Hort Environ Biotechnol 2012; 53: 316-9. [http://dx.doi.org/10.1007/s13580-012-0081-8]

[5] Sayeh JM, Fatemeh N. Pollen and ather development in Ziziphus jujuba L. (Rhamnaceae). Adv Environ Biol 2012; 6: $2339-43$.

[6] Yao S. Unique fruit development of ornamental 'Teapot' jujube. Horttechnology 2013; 23: 364-8.

[7] Rouhakhsh H, Davarynejad G, Rahemi M, et al. In vitro pollen grain germination and tube growth of ten Iranian Jubube (Ziziphus jujuba) cultivars. Not Sci Biol 2014; 6: 158-62. [http://dx.doi.org/10.15835/nsb.6.2.9266]

[8] Qu Z, Wang Y, Zhou J. Preliminary study on flower bud differentiation of jujube. J Heibei Agric University 1963; 2(1): 7-15.

[9] Liu M, Wang J, Ping L, et al. Historical achievements and frontier advances in the production and research of chinese jujube (Ziziphus jujuba) in China. Acta Hortic Sin 2015; 42: 1683-98. [http://dx.doi.org/10.1007/s10114-015-4669-7]

[10] Yao S. Past, Present, and future of jujubes Chinese dates in the United States. HortScience 2013; 48: 672-80.

[11] Rong H, Qi Z, Xi J. Observation on flower-bud morph differentiation and flower structure on jujube. J Tarim Univ 2009; 21 : 11-4.

[12] Zou F, Yuan D, Duan J, et al. Sporogenesis and gametophytes development in Ziziphus jujuba Mill cv. Jinsi No.4. Non-wood. For Res 2013; 
31: $26-31$.

[13] Han Z, Yuan D, Chen W, et al. Effects of different nutrient elements on pollen germination and tube growth in Ziziphus jujuba Mill. Acta Agriculturae Universitatis Jiangxiensis 2014; 36: 357-63.

[14] Yuan D, Wang S, Gu Z, et al. Blossom and fruit drop and anatomic observations on embryonic development of Ziziphus jujuba Mill. cv. 'Hunanjidanzao'. ISHS Acta Hortic 2009; 840: 347-55. [http://dx.doi.org/10.17660/ActaHortic.2009.840.48]

[15] Zou F, Guo S, Xie P, et al. Megasporogensis and development of female gametophyte in chinese chestnut (Castanea mollissima) cultivar 'Yanshanzaofeng'. Int J Agric Biol 2014; 16: 1001-5.

[16] Zou F, Chen S-L, Yuan D-Y, et al. Microsporogenesis, megasporogensis and male and female gametophyte development in Feijoa sellowiana (Myrtaceae). Int J Agric Biol 2016; 18: 637-42. [http://dx.doi.org/10.17957/IJAB/15.0140]

[17] Duna J, Lin Z, Li F, et al. Cloning and expression analysis of ZjMADS1-box gene related to floral organ development in Chinese jujube (Ziziphus jujuba Mill.). Xibei Zhiwu Xuebao 2012; 32: 2374-82.

[18] Cao S, Zhang Q, Shun W. Advances in research on the mechanism of flower-bud differentiation of fruit trees. J Fruit Sci 2003 ; 20 : 345-50.

[19] Meng Y, Sun H, Cao Q, et al. Differentiation of flower bud and deciduous fruit-bearing shoot and its development in Hupingzao jujube cultivar. J Fruit Sci 2009; 26: 487-91.

[20] Chen Y. An introduction to Chinese jujube. Beijing: China Science and Technology Press 1991; pp. 1-30.

[21] Wang L, Sun H, Meng Y, et al. The distribution and change of the sugar matter in the flower during the development process of the Z. jujuba Mill. J Shanxi Agric Sci 2009; 37: 33-7.

[22] Tel-Zur N, Schneider B. Floral biology of Ziziphus mauritiana (Rhamnaceae). Sex Plant Reprod 2009; $22(2)$ : $73-85$. [http://dx.doi.org/10.1007/s00497-009-0093-4] [PMID: 20033458]

[23] Meir M, Ransbotyn V, Raveh E, Barak S, Tel-Zur N, Zaccai M. Dormancy release and flowering time in Ziziphus jujuba Mill., a direct flowering fruit tree, has a facultative requirement for chilling. J Plant Physiol 2016; 192: 118-27. [http://dx.doi.org/10.1016/j.jplph.2016.02.002] [PMID: 26949231]

[24] Niu H, Zhang H, Yuan B, et al. Flower formation and endogenous hormones dynamic in Chinese jujube. Acta Hortic Sin 2015; 42 : 655-64.

[25] Asatryan A, Tel-Zur N. Intraspecific and interspecific crossability in three Ziziphus species (Rhamnaceae). Genet Resour Crop Evol 2014; 61: 215-33.

[http://dx.doi.org/10.1007/s10722-013-0027-8]

[26] Teaotia SS, Chauhan RS. Flowering, pollination, fruit set and fruit drop studies in ber (Ziziphus mauritiana Lamk.) I. Floral biology. Punjab J Hort 1963; 3: 60-70.

[27] Teaotia SS, Chauhan RS. Flowering, pollination, fruit set and fruit drop studies in ber (Ziziphus mauritiana Lamk.) II. Pollination, fruit set, fruit development and fruit drop. Ind J Hort 1964; 2: 40-5.

\section{(C) 2017 Zou et al.}

This is an open access article distributed under the terms of the Creative Commons Attribution 4.0 International Public License (CC-BY 4.0), a copy of which is available at: (https://creativecommons.org/licenses/by/4.0/legalcode). This license permits unrestricted use, distribution, and reproduction in any medium, provided the original author and source are credited. 